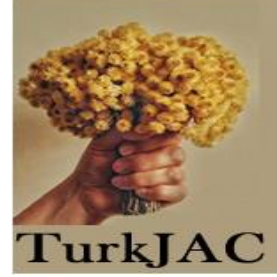

\title{
Antimicrobial, antioxidant, tyrosinase activities and volatile compounds of the essential oil and solvent extract of Epilobium hirsutum L. growing in Turkey
}

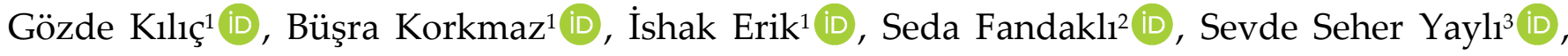 \\ Özlem Faiz ${ }^{4}$ iD, Şengül Alpay Karaoğlu ${ }^{5}$ (D), Nurettin Yaylı ${ }^{*}$ iD
}

${ }^{1}$ Karadeniz Technical University, Faculty of Pharmacy, Department of Pharmacognosy, Trabzon, Türkiye ${ }^{2}$ Avrasya University, Faculty of Health Sciences, Department of Nutrition and Dietetic, Trabzon, Türkiye ${ }^{3}$ Karadeniz Technical University, Faculty of Sciences, Department of Biology, Trabzon, Türkiye

${ }^{4}$ Recep Tayyip Erdogan University, Faculty of Arts and Sciences, Department of Chemistry, Rize, Türkiye ${ }^{5}$ Recep Tayyip Erdogan University, Faculty of Arts and Sciences, Department of Biology, Rize, Türkiye

\begin{abstract}
The essential oil (EO), solid phase micro extraction (SPME), and SPME of $n$-hexane extract of Epilobium hirsutum L. were analyzed by GC-FID/MS. A total of 35, 20, and 32 compounds were identified from E. hirsutum, accounting for 98.2\% in hydrodistillation (HD), 97.6\% in SPME, and 98.8\% in SPME of $n$-hexane extract, respectively. The EO and SPME consisted mainly of alcohol (HD: 51.5\% vs. SPME: $30.8 \%$ ). Aromatic hydrocarbons $(57.1 \%)$ were the major compounds for the SPME of $n$-hexane extract. Monoterpenes were the minor constituents for the EO (2.3\%) and SPME (3.1\%) of the E. hirsutum. (Z)-3-Hexene-1-ol (46.5\%), (Z)-3-hexenyl acetate (18.2\%), and cyclohexanone (38\%) were major compounds for the EO, SPME, and SPME of $n$-hexane of the E. hirsutum, respectively. The comparative study gave that the total amount of monoterpenoids (6.3\%) was found only in the EO of E. hirsutum. The antimicrobial activities of EO and solvent extracts (n-hexane, methanol, and water) of E. hirsutum were screened in vitro against nine microorganisms. The EO resulted in the best activity $(10 \mathrm{~mm})$ against Escherichia coli. Antimicrobial activity for the methanol extract of E. hirsutum against the Pseudomonas aeruginosa, Enterococcus faecalis, and Mycobacterium smegmatis was found to be $12 \mathrm{~mm}, 12$ $\mathrm{mm}$, and $16 \mathrm{~mm}$ inhibition zone, respectively. Methanol extract gave moderate activity against the Yersinia pseudotuberculosis, Staphylococcus aureus, and Bacillus cereus within 6-8 mm, respectively. Antioxidant activity of water extract was found to be $12.77 \pm 0.02 \mu \mathrm{M}$ (CUPRAC) and 0.034 $\mathrm{mg} / \mathrm{mL}$ ( $\left.\mathrm{IC}_{50}, \mathrm{DPPH}\right)$. IC 50 values for the tyrosinase enzyme inhibitory activity for the methanol and water extracts were determined to be $0.20 \pm$ $0.01 \mu \mathrm{g} / \mathrm{mL}$ and $0.16 \pm 0.09 \mu \mathrm{g} / \mathrm{mL}$, respectively.
\end{abstract}

Keywords: Epilobium hirsutum, essential oil, GC-FID/MS, SPME, antimicrobial, antioxidant, tyrosinase activity

\section{Introduction}

The Epilobium genus is represented by more than 185 herbaceous perennial species belongs to the Onagraceae family [1,2] which are distributed in North Africa, most of Europe, parts of Asia, North America, and Australia. It grows in wet habitats up to 2,500 meters above sea level [1,2]. The traditional name of Epilobium species is "Yaki Otu" in Turkey. Young shoots of Epilobium species are consumed as food. These species have been used in traditional medicine for the treatment of mouth wounds [3]. An ointment that is prepared from the leaf of Epilobium species has been used for skin disorders. Epilobium taxa are one of the best known traditional used medicinal plants for prostate and gastrointestinal disorders in Turkey and worldwide [4-9]. Epilobium hirsutum L. (syn. Chamaenerion hirsutum (L.) Scop.) is native throughout the world [1,2]. The chemical constituents of Epilobium species have been described and polyphenolic compounds (phenolic acids, steroids, tannins, and flavonoids) were the main constituents occurring in Epilobium herb [10-22]. The extracts of Epilobium taxa have been reported to exhibit antiproliferative [21], antiaging [22], antioxidants [2326], anti-inflammatory [27], antimicrobial [28-32], analgesic, prostate cancer healer $[33,34]$, antiproliferative [21], antinociceptive [35], anti-diarrhoeal, anti-motility, and anti-secretory [36] properties. The pharmacological and therapeutic potentials of $E$. hirsutum have given as a review report $[4,6]$. In the
Citation: G. Kılıç, B. Korkmaz, İ. Erik, S. Fandaklı, S. S. Yaylı, Ö. Faiz, Ş. Alpay Karaoğlu, N. Yaylı, Antimicrobial, antioxidant, tyrosinase activities and volatile compounds of the essential oil and solvent extract of Epilobium hirsutum L. growing in Turkey, Turk J Anal Chem, 2(2), 2020, 87-94.
*Author of correspondence: yayli@ktu.edu.tr

Phone: +90 (533) 31531 87, Fax: +90 (462) 3256717

Received: October 20, 2020

Accepted: November 21, 2020 
literature, the chemical composition and antibacterial activity (Staphylococcus aureus, Bacillus cereus, Salmonella enterica, and Escherichia coli) of the essential oil of $E$. hirsutum from Iran were mentioned and the most abundant component was reported as pulegone, constituting $74.6 \%$ of the oil [37]. The volatile contents for SPMEs extracts, tyrosinase, and some of the antimicrobial effects (nine microorganisms) of the essential oil and solvent extracts of E. hirsutum growing in Turkey have not been previously reported. This work aims to analyze the chemical variation, antimicrobial, antioxidant, and tyrosinase activities of the EO and solvent extracts (methanol and water) of E. hirsutum. According to our literature survey, this is the first comparative study of the phytochemical composition of E. hirsutum growth in Turkey. Such a study is needed to show how the different extraction methods affect the volatile constituents and different chemotypes.

\section{Experimental}

\subsection{Plant material}

Wild grown E. hirsutum was collected from $1450 \mathrm{~m}$ above sea level in August 2018 from Koyulhisar-Sivas (SE part of Turkey). The fresh plant materials air-dried in the shade at room temperature and analyzed as soon as possible. The plant was authenticated by Prof. K. Coşkunçelebi by using Flora of Turkey [2]. The voucher specimen was deposited and stored in the Herbarium of Biology, Karadeniz Technical University.

\subsection{Hydrodistillation apparatus and procedure}

Dried grounded aerial part of E. hirsutum (125 g) was used to obtain essential oil by hydrodistillation (HD) using a modified Clevenger-type apparatus with a cooling bath $\left(-15^{\circ} \mathrm{C}\right)$ system $(3 \mathrm{~h})$ (yield $\left.(\mathrm{w} / \mathrm{w}): 18.3 \mathrm{mg}\right)$. The HD oil was extracted with $n$-hexane (HPLC grade, $0.5 \mathrm{ml}$ ) and dried over anhydrous $\mathrm{Na}_{2} \mathrm{SO}_{4}$, and kept in sterilized dark glass bottles in the refrigerator at $4{ }^{\circ} \mathrm{C}$ before the analysis [38-39].

2.3.n-Hexane, methanol, and water extracts of $E$. hirsutum

Dried grounded plant (5 g, each) was put into three different flasks $(50 \mathrm{~mL})$ and extracted three times with an analytical grade $n$-hexane, methanol, and water solvents $(10 \mathrm{ml} \times 3 ; 12 \mathrm{~h}$ each), respectively. After the suction filtration, the same extracts were combined. $n$ Hexane and methanol were evaporated at the $40{ }^{\circ} \mathrm{C}$ to give crude $n$-hexane $(46.2 \mathrm{mg})$ and methanol $(96.5 \mathrm{mg})$. Water was lyophilized to obtain crude water extract (75 $\mathrm{mg}$ [38].

\subsection{Solid-phase microextraction (SPME) analysis}

The blended dried plant (1.2 g each) and $n$-hexane extract $(30 \mathrm{mg})$ of E. hirsutum were placed in a sealed SPME vial $(10 \mathrm{~mL})$ with a silicone-rubber septum cap then submitted to a SPME device (Supelco, USA). A DVB/Carboxen/PDMS coating fiber was employed to receive volatile components. The condition of SPME fibers was carried out for $5 \mathrm{~min}$ at $250{ }^{\circ} \mathrm{C}$ in the GC injector. Extraction was made with magnetic stirring at $80^{\circ} \mathrm{C}$. The incubation and extraction time were 5 and 10 min, respectively. Fiber with extract of volatile compounds was subsequently injected into the GC injector. GC-FID/MS analyzes were performed using a Shimadzu QP2010 Ultra mass selective detector attached to the 2010 Plus chromatograph. Helium was employed as a carrier gas at a flow rate of $1 \mathrm{~mL} / \mathrm{min}$. The injection was carried out in split mode $(1: 30)$ at $230^{\circ} \mathrm{C}$. The sample was analyzed and reported. The temperature, incubation, and extraction time were optimized according to the studies in the literature [38-40].

\subsection{Gas chromatography-Mass spectrometry (GC-FID/ MS)}

EO analysis was carried out using a Shimadzu QP2010 ultra GC-FID/MS, Shimadzu 2010 plus FID, fitted with a PAL AOC-5000 plus autosampler, and Shimadzu Class5000 Chromatography Workstation software. The separation was analyzed using a Restek Rxi-5MS capillary column $(30 \mathrm{~mm} \times 0.25 \mathrm{~mm} \times 0.25 \mu \mathrm{m})$ (USA). Essential oil injection to GC-FID/MS was performed in split mode $(1: 30)$ at $230{ }^{\circ} \mathrm{C}$. The essential oil solution $(1 \mu \mathrm{L})$ in $n$-hexane was injected and analyzed with the column held initially at $60{ }^{\circ} \mathrm{C}$ for $2 \mathrm{~min}$ and then increased to $240{ }^{\circ} \mathrm{C}$ with a $3{ }^{\circ} \mathrm{C} / \mathrm{min}$ heating ramp and the final temperature of $250{ }^{\circ} \mathrm{C}$ was held for 4 minutes. Helium (99.999 \%) was used as carrier gas with a constant flow-rate of $1 \mathrm{~mL} / \mathrm{min}$. Detection was determined in electronic impact mode (EI); ionization voltage was at $70 \mathrm{eV}$, and scan mode $(40-450 \mathrm{~m} / \mathrm{z})$ was used for mass acquisition. Samples were analyzed and mean reported [41-42].

\subsection{Identification of volatile constituents}

Retention indices and chromatographic peaks were used to identify the volatile constituents. Retention indices were compared to $\mathrm{C}_{6}-\mathrm{C}_{32}$ alkane standards. Individual chromatographic peaks in the mass spectra were compared with the commercial libraries (FFNSC1.2, W9N11, and NIST) [38-43].

\subsection{Antimicrobial activity assessment (Agar-well diffusion method)}

All test microorganisms which were obtained from the Hifzissihha Institute of Refik Saydam (Ankara, Turkey) were Bacillus cereus 709 ROMA, Candida albicans ATCC 
60193, Enterococcus faecalis ATCC 29212, Escherichia coli ATCC 25922, Mycobacterium smegmatis ATCC607, Pseudomonas auroginosa ATCC 27853, Saccharomyces cerevisiae RSKK 251, Staphylococcus aureus ATCC 25923, and Yersinia pseudotuberculosis ATCC 911. T, he plant extracts were dissolved in $n$-hexane, methanol, and water to prepare extracts stock solution. Antimicrobial susceptibility of the EO, n-hexanes, methanol, and water extracts of E. hirsutum were screened using the agar-well diffusion method [44-45]. Each bacterium and the yeast were cultured in Mueller Hinton (MH) (Difco, Detroit, MI) broth and yeast extract broth, respectively. Then the microorganisms were diluted nearly 106 colony-forming unit (cfu) per mL. For yeast-like fungi, Sabouraud Dextrose Agar (SDA) (Difco, Detriot, MI) was used. Microorganisms were "flood-inoculated" onto $\mathrm{MH}$ and SD agars and dried under aseptic conditions. $50 \mu \mathrm{L}$ of essential oil, solvent extracts of E. hirsutumwere delivered into wells (diameter $=5 \mathrm{~mm}$ ) opened on agar plates, and incubated at $35{ }^{\circ} \mathrm{C}$ for $18 \mathrm{~h}$. The growing of Mycobacterium smegmatis was made for 3 to 5 days on MHA plates at $35{ }^{\circ} \mathrm{C}$. Microbial activity was evaluated by measuring the zone diameters. Antimicrobial agents such as Ampicillin $(10 \mu \mathrm{g} / \mathrm{mL})$, streptomycin $(10 \mu \mathrm{g} / \mathrm{mL})$, and fluconazole ( $5 \mu \mathrm{g} / \mathrm{mL}$ ) were used as the positive control. All tests were carried out in triplicates.

\subsection{Determination of antioxidant capacity (CUPRAC and DPPH)}

In vitro antioxidant property of E. hirsutumaqueous extract was tested using 2,2-diphenyl-1-picrylhydrazyl scavenging (DPPH). Cupric reducing activity known as cupric reducing antioxidant capacity (CUPRAC) methods. CUPRAC assay was performed according to the literature [46]. In a test tube, $1 \mathrm{ml}$ of each $1.0 \times 10^{-2} \mathrm{M}$ $\mathrm{CuCl}_{2}, 7.5 \times 10^{-3} \mathrm{M}$ neocuproine and $1.0 \mathrm{M}$ ammonium acetate buffer ( $\mathrm{pH} 7.0$ ), and $1.1 \mathrm{~mL}$ of E. hirsutum aqueous extract at different concentrations was mixed together to make the final volume $4.1 \mathrm{~mL}$. After 30 minutes incubation period, the absorbance was read 450 nm using Shimadzu UV-1600 spectrophotometer. Trolox was employed as a reference standard in the measurements. Results were expressed as $\mu \mathrm{mol}$ Trolox/g dry weight of E. hirsutum extract ( $\mu$ mol Trolox/g DW). The DPPH radical scavenging capacity for the aqueous extract of E. hirsutum was tested by the spectrometric method. The assay mixture $(1.5 \mathrm{~mL})$, methanolic DPPH solution $(0.75 \mathrm{~mL}, 0.1 \mathrm{mM})$ and different concentrations of extracts $(0.75 \mathrm{~mL})$ was prepared. The mixture was incubated in the dark at room temperature for $50 \mathrm{~min}$ and absorbance was measured at $517 \mathrm{~nm}$ using Shimadzu UV-1600 spectrophotometer [47]. The assay was also performed for a control mixture without $E$. hirsutum extract but with extraction solvent. Trolox was used as a positive control. The following equation was used to calculate the inhibition of DPPH radical activity.

$$
\% \text { Inhibition }=\%=\left[1-\left[\frac{\left(A_{\text {sample }}-A_{\text {sample blank }}\right)}{A_{\text {control }}}\right]\right] x 100
$$

\subsection{Tyrosinase inhibition assay}

The tyrosinase inhibition for the aqueous, methanol, nhexane extracts and essential oil of E. hirsutum was determined by pursuing the method described in the literature [48] with some modifications. $800 \mu \mathrm{L}$ phosphate buffer (50 mM, pH 6.8), $15 \mu \mathrm{L}$ mushroom tyrosinase $(2500 \mathrm{U} / \mathrm{mL})$ (T3824 SIGMA Tyrosinase from mushroom), and plant extract at different concentrations were mixed and incubated at room temperature for ten minutes. At the end of the incubation period $100 \mu \mathrm{L}$ of $10 \mathrm{mM}$ L-DOPA (3,4-dihyroxy-L-phenylalanine) solution was added and incubated for 30 minutes at room temperature. The absorbance of the formed dopachrome was measured at $470 \mathrm{~nm}$ with references at 700 nm using Shimadzu UV-1600 spectrophotometer. Kojic acid was used as a positive control. The extract concentration giving $50 \%$ (IC50) of the original tyrosinase activity was determined.

\section{Results and discussion}

\subsection{Chemical composition of the EO and SPME}

GC-FID/MS analysis of the EO, SPME, and SPME of $n$ hexane extract of E. hirsutum revealed a total of 35, 20, and 32 volatile compounds, representing 98.2\%, 97.6\%, and $98.8 \%$, respectively. The volatile organic compounds of the EO, and SPMEs of E. hirsutum, their retention indices and percentages are listed in Table 1. Volatile compounds have been listed in the order of elution on the Rxi-5MS column used (24-27), which were identified by comparison of the registered mass spectrum libraries (NIST, Wiley7NL, FFNSC1.2, and W9N11), and by using the Kovats index [28-34]. A total of 77 volatile compounds were detected in the EO and SPMEs of E. hirsutum by the GC-FID/MS analysis. As was expected, the higher diversity of compounds was determined in the EO rather than SPMEs (Table 1).

The qualitative and quantitative differences were observed between EO and SPMEs due to the different extractions used. The identified constituents involve different classes of chemical compounds, including monoterpenes, monoterpenoids, sesquiterpenes, aromatic hydrocarbons, aliphatic hydrocarbons, terpene related compounds, aldehydes, ketones, esters, alcohols, acids, and other hydrocarbons. 
Table 1. Identified VOCs form the EO and SPMEs of E. hirsutum growing in Turkey

\begin{tabular}{|c|c|c|c|c|c|c|c|c|c|c|c|c|c|}
\hline \multirow{2}{*}{\multicolumn{2}{|c|}{ No Compounds }} & \multirow{2}{*}{$\mathbf{R I}^{*}$} & \multirow{2}{*}{$\mathbf{R I}^{\mathbf{a}}$} & \multicolumn{3}{|c|}{$(\%)^{b}$} & \multirow{2}{*}{\multicolumn{2}{|c|}{ No Compounds }} & \multirow{2}{*}{$\mathbf{R I}^{*}$} & \multirow{2}{*}{$\mathbf{R I}^{\mathbf{a}}$} & \multicolumn{3}{|c|}{$(\%)^{b}$} \\
\hline & & & & A1 & A2 & A3 & & & & & A1 & A2 & A3 \\
\hline 1 & Toluene & 782 & 782 & 4.1 & - & 6.8 & 65 & Geranyl acetone & 1453 & 1450 & 0.3 & - & - \\
\hline 2 & Octane & 800 & 802 & - & - & 0.1 & 66 & (E)-Ethyl cinnamate & 1465 & 1467 & - & 0.6 & - \\
\hline 3 & Capronaldeyhde & 802 & 804 & 4.4 & 0.8 & - & 67 & (E)- $\beta$-ionone & 1487 & 1489 & 1.0 & - & - \\
\hline 4 & Butyl acetate & 814 & 813 & - & - & 0.5 & 68 & Pentadecane & 1500 & 1503 & 0.8 & - & - \\
\hline 5 & (E)-2-Hexenal & 852 & 853 & 1.8 & 1.4 & - & 69 & $\beta$-Bisabolene & 1509 & 1508 & - & - & 0.1 \\
\hline 6 & (Z)-3-Hexenol & 865 & 860 & 46.5 & 10.3 & - & 70 & Hexadecane & 1600 & 1602 & - & - & 0.1 \\
\hline 7 & Ethylbenzene & 871 & 870 & - & - & 1.2 & 71 & Hexahydrofarnesyl acetone & 1847 & 1850 & 0.7 & - & - \\
\hline 8 & Hexanol & 863 & 863 & - & 11.1 & - & 72 & Nonadecane & 1900 & 1901 & 0.5 & - & - \\
\hline 9 & 4-Methy-1-penten-3-ol & 870 & 874 & 5.0 & - & - & 73 & Heptadecanone & 1901 & 1906 & 0.3 & - & - \\
\hline 10 & 1,4-Dimethylbenzene & 878 & 878 & - & - & 7.0 & 74 & Hexadecanoik acid & 1966 & 1963 & 0.2 & - & - \\
\hline 11 & 2,3-Dimethyl-3-butenol & 894 & 895 & - & - & 1.3 & 75 & Manoyl oxide & 1989 & 1993 & 0.2 & - & - \\
\hline 12 & Cyclohexanone & 903 & 903 & - & - & 38.0 & 76 & Heneicosane & 2100 & 2100 & 1.1 & - & - \\
\hline 13 & Heptanal & 906 & 906 & 0.6 & 1.6 & - & 77 & Tricosane & 2300 & 2299 & 10.1 & - & - \\
\hline 14 & 1-Methylethylbenzene & 929 & 929 & - & - & 0.1 & \multirow{2}{*}{\multicolumn{4}{|c|}{ Chemical classes; }} & & & \\
\hline 15 & $\alpha$-Pinene & 940 & 939 & 1.7 & - & - & & & & & \multicolumn{3}{|c|}{$\%^{b}$ and $N^{c}$} \\
\hline 16 & 3-Ethyl-2-methylheptane & 942 & 941 & - & - & 0.1 & \multicolumn{4}{|c|}{ Monoterpene hydrocarbons } & $2.3: 3$ & $3.1: 2$ & - \\
\hline 17 & Propylbenzene & 960 & 957 & - & - & 2.0 & \multicolumn{4}{|c|}{ Monoterpenoids } & $6.3: 6$ & - & - \\
\hline 18 & (E)-2-Heptanal & 959 & 958 & 1.0 & - & - & \multicolumn{4}{|c|}{ Sesquiterpenes hydrocarbon } & - & $4.2: 1$ & $0.1: 1$ \\
\hline 19 & 1-Ethyl-3-methylbenzene & 968 & 965 & - & - & 10.8 & \multicolumn{4}{|c|}{ Aromatic hydrocarbons } & $5.0: 3$ & $6.7: 1$ & $57.1: 19$ \\
\hline 20 & Heptanol & 959 & 959 & - & 6.7 & - & \multicolumn{4}{|c|}{ Aliphatic hydrocarbons } & $12.0: 3$ & - & 1.3:8 \\
\hline 21 & 1-Ethyl-4-methylbenzene & 970 & 971 & - & - & 3.9 & \multicolumn{4}{|c|}{ Terpene related to compounds } & $2.7: 5$ & $1.0: 1$ & - \\
\hline 22 & $\beta$-Pinene & 978 & 972 & 0.5 & - & - & \multicolumn{4}{|c|}{ Aldehydes } & $16.5: 9$ & $29.7: 7$ & - \\
\hline 23 & 1-Etil-2-metilbenzen & 979 & 983 & - & - & 2.8 & \multicolumn{4}{|c|}{ Ketone } & $1.7: 3$ & - & $38.0: 1$ \\
\hline 24 & 6-Methyl-5-heptene-2-one & 981 & 977 & 0.9 & - & - & \multicolumn{4}{|c|}{ Esters } & - & 18.8:2 & $0.5: 1$ \\
\hline 25 & 2-Pentylfuran & 993 & 992 & 0.4 & 6.7 & - & \multicolumn{4}{|c|}{ Alcohols } & $51.5: 2$ & $30.8: 5$ & $1.3: 1$ \\
\hline 26 & 1,3,5-Trimethylbenzene & 996 & 997 & - & - & 17.0 & \multicolumn{4}{|c|}{ Acids } & $0.2: 1$ & - & - \\
\hline 27 & Octanal & 998 & 1002 & - & 0.5 & - & \multicolumn{4}{|c|}{ Others } & - & $3.3: 1$ & $0.5: 1$ \\
\hline 28 & (Z)-3-Hexenyl acetate & 1004 & 1005 & - & 18.2 & - & \multicolumn{4}{|c|}{ Total } & 98.2:35 & $97.6: 20$ & 98.8:32 \\
\hline
\end{tabular}

29 Hexyl acetate

30 (E,E)-2,4-Heptadienal

31 -Cymene

32 1,2,4-Trimethylbenzene

33 Limonene

34 Benzene acetaldeyhde

35 Indane

36 Eucalyptol

37 (Z)- $\beta$-Ocimene

38 1-Methyl-3-propylbenzene

39 1,4-Dimethylbenzene

10101011

10121012

10121016

10351036

$1031 \quad 1034$

10361036

10411040

10461046

10411046

10531052

40 1-Ethyl-3,5-dimethylbenzene

41 3-Methyldecane

10561056

42 1-Methyl-4-propylbenzene 10611068

43 Octanol

10631059

44 4-Ethyl-1,2-dimethylbenzene 10771078

45 1-Ethyll-2,4-dimethylbenzene 10831080

46 2-Ethyll-1.4-dimethylbenzene 10851086

47 Undecane 11001095

48 Nonanal 11011102

49 1-Ethyl-2,3-dimethylbenzene 11131108

50 1,2,4,5-Tetramethylbenzene 11311132

51 Camphor

52 Nonanol

11611161

$53 \alpha$-Phellandren-8-ol

11711168

54 Naphthalane

55 Terpinol-4-ol

11701170

11811179

11921191

$56 \alpha$-Terpinol

57 Dodecane

58 Decanal

$59 \beta$-Cyclocitral

60 2-(E)-Decenal

61 (Z)-3- Hexenyl tiglate

62 (E)- $\beta$-Damascenone

63 Tetradecane

64 (E)-Karofilen

65 Geranyl acetone

* Retention Index of references; ${ }^{\text {a }}$ Retention Index calculated with the RT relative to that of n-alkane $\left(\mathrm{C}_{6}-\mathrm{C}_{32}\right)$ series; ${ }^{\mathrm{b}}$ Percentages were obtained by FID peak-area normalization; c NC: Number of compounds; A1: HD; A2; SPME; A3: SPME $n$-hexane extract

The extractions of E. hirsutum had two effects on the composition of the plant, which are the quantitative changes of compounds and appearance/disappearance of volatiles. Some of the compounds, like 4-methy-1penten-3-ol, (E)-2-heptanal, $\beta$-pinene, $p$-cymene, $\alpha$ phellandren-8-ol, terpinol-4-ol, $\beta$-cyclocitral, $2-(E-$ decenal, (E)- $\beta$-damascenone, geranyl acetone, $(E)-\beta$ ionone, pentadecane, hexahydrofarnesyl acetone, nonadecane, heptadecanone, hexadecanoic acid, manoyl oxide, heneicosane, and tricosane were found only in $\mathrm{EO}$ of E. hirsutum. Whereas, hexanol, heptanol, octanal, (Z)3-hexenyl acetate, hexyl acetate, (Z)- $\beta$-ocimene, octanol, nonanol, (Z)-3-hexenyl tiglate, $(E)$-carofilen, and $(E)$ ethyl cinnamate were existed only in the SPME of $E$. hirsutum. Octane, butyl acetate, ethylbenzene, 1,4dimethylbenzene,

2,3-dimethyl-3-butenol, cyclohexanone, 1-methylethylbenzene, 3-ethyl-2methylheptane, propylbenzene, 1-ethyl-3methylbenzene, 1-etil-2-metilbenzen, 1,2,4trimethylbenzene, indane, 1-methyl-3-propylbenzene, 1,4-dimethylbenzene, 1-ethyl-3,5-dimethylbenzene, 3methyldecane, 1-methyl-4-propylbenzene, 4-ethyl-1,2dimethyl-benzene, 1-ethyll-2,4-dimethylbenzene, 2ethyll-1.4-dimethylbenzene, undecane, 1-ethyl-2,3dimethylbenzene, 
naphthalane, dodecane, tetradecane, $\beta$-bisabolene, and hexadecane were present only in the SPME of $n$-hexane extract of E. hirsutum. The quantitative composition of volatiles varied depending on the sample origin. Possibly the different extraction methods (HD and SPME) cause the variation of chemical components as in the literature [42-46]. Thus, the existence of different chemotypes in the EO, SPME, and SPME of $n$-hexane extract of E. hirsutum were identified. Comparative analysis for the extracts of the plant showed that the amount of alcohol (HD, 51.5\% vs SPME 30.8\%) was the major group of compounds in EO and SPME. Despite these, aromatic hydrocarbons were found to be major constituents of SPME of $n$-hexane extract of E. hirsutum. The numbers of the identified terpenes/terpenoids were greater in $\mathrm{EO}$ of E. hirsutum.

In the literature, the $\mathrm{EO}$ of E. hirsutum gave pulegone $(74.6 \%)$, menthofuran $(11.8 \%)$, and 1,8 -cineole $(2.4 \%)$ as the major constituents which we could not found. The other compounds were also so different than in our analysis [37]. The antibacterial activity of the EO has been mentioned against four bacterial species (Staphylococcus aureus, Bacillus cereus, Escherichia coli, and Salmonella enterica) and inhibition zone was $10 \mathrm{~mm}$ (3.1\%), $10 \mathrm{~mm}$ (3.1\%), $10 \mathrm{~mm}$ (25\%) and $10 \mathrm{~mm} \mathrm{(50 \% ),}$ respectively [37]. In the literature, in vivo and in vitro ethnopharmacological uses of Epilobium angustifolium, E. stevenii, and E. hirsutum explained and the probable wound-healing activity mechanism was mentioned [5]. A study related to the determination of sesquiterpene derivatives from the essential oil of E. hirsutum was also reported [12]. In the E. hirsutum seed oil palmitic, stearic, oleic, linoleic, $\gamma$-linolenic, and $\alpha$-linolenic acids were reported and palmitic and linoleic acids were mentioned to be dominant compounds [15].

It is known that the reduced cost of extraction is advantageous for the SPME method in terms of decomposition, time, and energy. The variations in the VOCs on Epilobium taxa may be due to environmental, storage, and analysis conditions. Results of this work, extractions methods that used had remarkable changes in volatiles. The differences in volatile composition were also demonstrated by the literature [49-50]. However, using the different extraction methods let the appearance of new compounds had a positive effect on the quality of E. hirsutum. (Z)-3-Hexene-1-ol (46.5\%), (Z)-3-hexenyl acetate (18.2\%), and cyclohexanone (38\%) were major compounds for the EO, SPME, and SPME of n-hexane of the E. hirsutum, respectively. It was found that only the EO of E. hirsutum rich in monoterpenes/monoterpenoids which showed significant inhibitory activity against some fungi, like $E$. coli, E. faecalis, C. albicans, and S. cerevisiae. However, no activity was reported against the $Y$. pseudotuberculosis, $P$. aeruginosa, S. aureus, B. cereus, and $M$. smegmatis. The evaluation of antimicrobial activities for the pure compounds of E. hirsutum was beyond the scope of this work. However, according to the experimental results and the above mentioned published data [4-37], the volatile compounds and solvent extracts of E. hirsutum also could be of therapeutic value.

\subsection{Biological activities}

\subsubsection{Antimicrobial activity}

Antimicrobial activities of the EO and solvent extracts (n-hexane, methanol, and water) of E. hirsutum were screened by using the agar well diffusion method with the microorganisms against Escherichia coli, Yersinia pseudotuberculosis, P. auroginosa, Enterococcus faecalis, S. aureus, B. cereus, M. smegmatis, C. albicans, and Saccharomyces cerevisiae [44-45]. In general, EO and methanol extract showed moderate antimicrobial activities with the inhibition zone in the range of 6-16 $\mathrm{mm}$ against E. coli, Y. pseudotuberculosis, P. aeruginosa, E. faecalis, S. aureus, B. cereus, M. smegmatis, C. albicans, and S. cerevisiae, respectively (Table 2 ).

Table 2. Antimicrobial activity of the EO and methanol extract of $E$. hirsutum.

\begin{tabular}{|c|c|c|c|c|c|c|c|c|c|c|}
\hline \multirow{3}{*}{$\begin{array}{l}\text { Sample } \\
\text { Extracts }\end{array}$} & \multirow{3}{*}{$\begin{array}{l}\text { Const. } \\
(\mu \mathrm{g} / \mathrm{ml})\end{array}$} & \multicolumn{9}{|c|}{ Microorganisms and inhibition zone (mm) } \\
\hline & & \multicolumn{3}{|c|}{$\begin{array}{l}\text { Gram (-) } \\
\text { Bacteria }\end{array}$} & \multicolumn{3}{|c|}{$\begin{array}{c}\text { Gram (+) } \\
\text { Bacteria }\end{array}$} & \multirow{2}{*}{$\begin{array}{c}\text { No G } \\
M s\end{array}$} & \multicolumn{2}{|c|}{$\begin{array}{c}\text { Yeast } \\
\text { Mush. }\end{array}$} \\
\hline & & Ec & $Y p$ & $P a$ & Ef & $S a$ & $B c$ & & $\mathrm{Ca}$ & $S c$ \\
\hline $\mathrm{EO}$ & 18.26 & 10 & - & - & 6 & - & - & - & 6 & 6 \\
\hline $\mathrm{CH}_{3} \mathrm{OH}$ & 96.50 & - & 8 & 12 & 12 & 6 & 8 & 16 & - & - \\
\hline Amp. & 10 & 10 & 10 & 18 & 10 & 35 & 15 & & & \\
\hline Strep. & 10 & & & & & & & 35 & & \\
\hline Flu. & 5 & & & & & & & & 25 & 25 \\
\hline
\end{tabular}

Ec: E. coli, Yp: Y. pseudotuberculosis, Pa: P. aeruginosa, Sa: S. aureus, Ef: E. faecalis, Bc: B. cereus, Ms: M. smegmatis, Ca: C. albicans, Sc: S. cerevisiae, Amp.: Ampicillin, Strep.: Streptomycin, Flu.: Fluconazole, $(-)$ : no activity of test concentrations.

The best activity was observed for the EO against $E$. coli with $10 \mathrm{~mm}$ inhibition. The methanol extract of gave better activity against the $P$. aeruginosa, E. faecalis, and $M$. smegmatis with 12,12, and $16 \mathrm{~mm}$ inhibition zones, respectively. Therefore, the bactericidal activity of EOs and the solvent extract obtained from E. hirsutum may be mainly related to the high content of alcohols and aldehydes. Other compounds (Table 1), which were also present in the samples, were reported to have antibacterial activities, may also collectively have a remarkable contribution to the bactericidal activities of the EO and methanol extracts. The antibacterial activity variations may be due to factors such as composition and concentration of EO and solvent extracts. The $n$-Hexane and water extracts of E. hirsutum did not show antimicrobial activity against all tested microorganisms. In the literature, antibacterial, antifungal, antioxidant activities, total phenolic content, postmenopausal effect, 
and prostate cancer activity for the solvent extracts of $E$. hirsutum had reported [34].

\subsubsection{Antioxidant (CUPRAC and DPPH) activities}

CUPRAC is a method used to measure total antioxidant capacity based on the Copper (II) reduction capacity of antioxidants [50]. In the CUPRAC method, a concentration-absorbance graph for Trolox as the reference standard and aqueous extract of E. hirsutum were generated. The slopes obtained from the graphs of the sample were scaled to the slope of the standard graph of Trolox. The Trolox Equivalent Antioxidant Capacity (TEACCUPRAC) value was calculated to be $12.77 \pm 0.02$ ( $\mu$ mol Trolox/g DW). The DPPH is a stable free radical antioxidant method that produces a violet color in methanol, shows maximum absorption at wavelength 515-520 nm. When DPPH methanol solution meets an antioxidant, its color is reduced to yellow [51]. THE remaining DPPH radical in a reaction mixture is gives the radical scavenging potential of a sample. When the DPPH method was applied to E. hirsutum aqueous extract the $\mathrm{IC}_{50}$ was calculated to be $0.034 \pm 0.002 \mathrm{mg} / \mathrm{mL}$. The IC 50 calculated for the positive standard Trolox is 0 . $120 \pm 0.008 \mathrm{mg} / \mathrm{mL}$. CUPRAC and DPPH antioxidant capacity revealed that $E$. hirsutum aqueous extract seems to have a high radical scavenging effect due to the poly phenolic compounds [12-20] when compared to the Trolox standard.

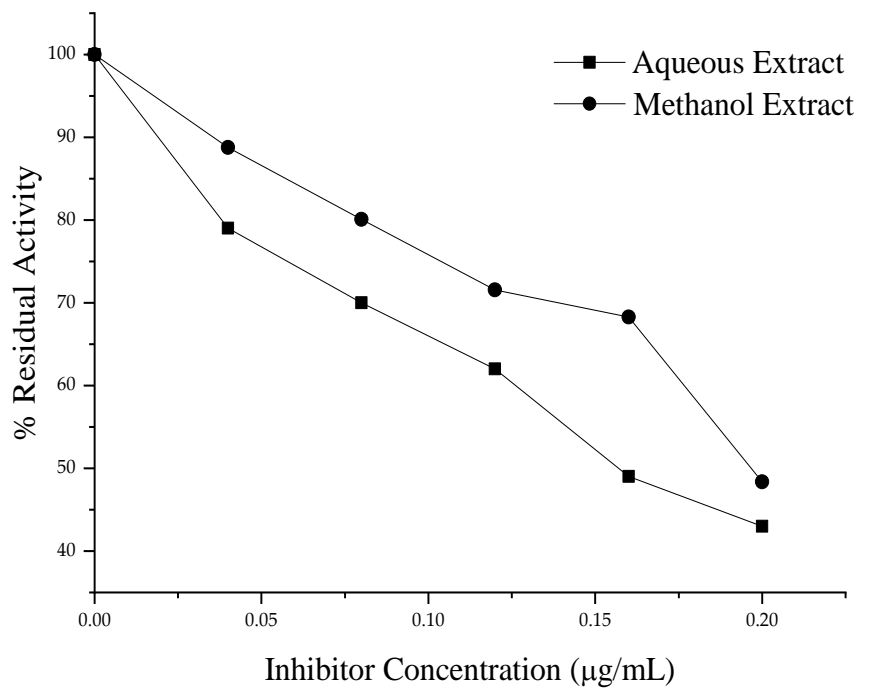

Figure 1. Tyrosinase activity for the methanol and water extracts of $E$. hirsutum growing in Turkey

\subsubsection{Tyrosinase activity}

Tyrosinase inhibitors have commercial potential in cosmetic industries because of their capability to reduce the melanization of human skin [48]. The aqueous, methanol, $n$-hexane extracts, and essential oils of $E$. hirsutum were monitored for their mushroom tyrosinase inhibition potentials. $n$-Hexane extract and essential oil did not possess any effect against tyrosinase. The aqueous and methanol extracts of E. hirsutum inhibited the mushroom tyrosinase at different ratios (Figure 1). The results showed that aqueous and methanol extracts of E. hirsutum had dose-dependent inhibitory effects on mushroom tyrosinase activity. The $\mathrm{IC}_{50}$ values for tyrosinase inhibition were obtained as $0.20 \pm 0.01 \mu \mathrm{g} / \mathrm{mL}$ and $0.16 \pm 0.09 \mu \mathrm{g} / \mathrm{mL}$ for methanol and aqueous extracts, respectively. The $\mathrm{IC}_{50}$ value for the reference compound (Kojic acid) was $3.10 \pm 0.20 \mu \mathrm{g} / \mathrm{mL}$. When we compare our results with the tyrosinase inhibitory activity for the leaf extracts of Hyaenanche globosa, Myrsine africana, and Aristotelia chilensis, it is seen that there is a better tyrosinase effect $[51,52]$.

\section{Conclusion}

A total of 77 constituents were characterized by the EO and SPMEs of the plant which showed variation to contain different volatile compounds. The amounts of terpenoid compounds identified by EO and SPME were greater in SPME of $n$-hexane extract of E. hirsutum. (Z)3-Hexene-1-ol (46.5\%), (Z)-3-hexenyl acetate (18.2\%), and cyclohexanone (38\%) were the major compounds for the EO, SPME, and SPME of $n$-hexane of the E. hirsutum which showed that different extraction methods used, gave different components as in the literature. The EO and methanol extract gave activity against the E. coli, Y. pseudotuberculosis, P. aeruginosa, E. faecalis, S. aureus, B. cereus, M. smegmatis, C. albicans, and $S$. cerevisiae within the range of 6-16 $\mathrm{mm}$, respectively. In general, the greatest activity of the $\mathrm{EO}$ was observed $10 \mathrm{~mm}$ value against E. coli. coli. Methanol extract gave better antimicrobial activity against the $\mathrm{M}$. smegmatis was determined to be $16 \mathrm{~mm}$ value. Therefore, antioxidant antimicrobial and tyrosinase activities' overall results suggest that EO and solvent extracts of E. hirsutum may have promising prospects for pharmaceutical, food, and other industrial applications. In a further study, activity guided isolation and purification could be carried out.

\section{Acknowledgements}

Thanks to Karadeniz Technical University for the financial support.

\section{Disclosure statement}

No potential conflict of interest was reported by the author(s).

\section{References}

[1] D.A. Baum, K.J. Sytsma, P.C. Hoch, A phylogenetic analysis of Epilobium (Onagraceae) based on nuclear ribosomal DNA sequences, Syst Bot, 19, 1994, 363-388. 
[2] D. Chamberlain, P.H. Raven, Epilobium L., Flora of Turkey and The East Aegean Island, Editor: P.H. Davis, 1972, Scotland, Edinburgh University Press.

[3] N. Zeybek, U. Zeybek, Pharmaceutical Botany, 1994, Turkey, Ege University Faculty of Pharmacy Publication.

[4] T. Ege, The pharmacological and therapeutic potentials of Epilobium hirsutum L., Int J Pharm Sci Rev Res, 57, 2019, 20-23.

[5] S. Karakaya, I. Suntar, Ö.F. Yakinci, O. Sytar, S. Ceribasi, B. Dursunoglu, H. Ozbek, Z. Guvenalp, In vivo bioactivity assessment on Epilobium species: A particular focus on Epilobium angustifolium and its components on enzymes connected with the healing process, J Ethnopharmacol, 262, 2020, 113-207.

[6] S. Granica, J.P. Piwowarski, M.E. Czerwińska, A.K. Kiss, Phytochemistry, pharmacology and traditional uses of different Epilobium species J. (Onagraceae): a review, J Ethnopharmacol, 156, 2014, 316-346.

[7] L. Pirvu, V. Nicorescu, C. Hlevca, D.I. Udeanu, I. Nicorescu, Antimicrobial and synergistic activity of some whole and selective Epilobium hirsutum L. (great willowherb) extracts tested on standard and wild Staphylococcus aureus strains, Farmacia, 63, 2015, 690-695.

[8] A. Vitalone, J. McColl, D. Thome, L.G. Costa, B. Tita, Characterization of the effect of Epilobium extracts on human cell proliferation, Pharmacology, 69, 2003, 79-87.

[9] A. Sayik, A.S. Yusufoğlu, A. Leyla, G. Türker, B. Aydin, L. Arslan, Dna-binding, biological activities and chemical composition of wild growing Epilobium angustifolium L. extracts from Çanakkale, Turkey, J Turkish Chem Soc, 4, 2017, 811-840.

[10] I.A. Schepetkin, A.G. Ramstead, L.N. Kirpotina, J.M. Voyich, M.A. Jutila, M.T. Quinn, Therapeutic potential of polyphenols from Epilobium angustifolium (Fireweed), Phytother Res, 30, 2014, 12871297.

[11] S. Jürgenson, V. Matto, A. Raal, Vegetational variation of phenolic compounds in Epilobium angustifolium, Nat Prod Res 26, 2012, 1951- 1953.

[12] I. Nitescu, D. Cucu, D. Lapa, O. Contz, Studies on a new method for photochemical screening using chromatography of medicinal plants, Farmacia, 42, 1994, 41-43.

[13] D. Cando, D. Morcuende, M. Utrera, M. Estevez, Phenolic-rich extracts from Willowherb (Epilobium hirsutum L.) inhibit lipid oxidation but accelerate protein carbonylation and discoloration of beef patties, Eur Food Res Technol 238, 2014, 741-751.

[14] I. Remmel, L. Vares, L. Toom, V. Matto, A. Raal, Phenolic compounds in five Epilobium species collected from Estonia, Nat Prod Commun, 7, 2012, 1323-1324.

[15] M. Pelc, O. Kosakowska, Z. Weglarz, J. Przybyl, A. Geszprych, Sterols and fatty acids in the seeds of evening primrose (Oenothera sp.) and willow herb (Epilobium sp.), Herba Pol, 51, 2005, 20-24.

[16] M.A. Nawwar, M.S. Marzouk, W. Nigge, M. Linscheid, Highperformance liquid chromatographic/electrospray ionization mass spectrometric screening for polyphenolic compounds of Epilobium hirsutum - the structure of the unique ellagitannin epilobamide-A, J Mass Spectrom, 32, 1997, 645-654.

[17] J. De Pascual Teresa, B. Corrales, M. Grande, A review on presence of oleanolic acid in natural products, An Quim, 75, 1979, 135-139.

[18] S. Ivancheva, N. Manolova, J. Serkedjieva, V. Dimov, N. Ivanovska, Polyphenols from Bulgarian medicinal plants with anti-infectious activity, Basic Life Sci 59, 1992, 717-728.

[19] H.H. Barakat, S.A.M. Hussein, M.S. Marzouk, I. Merfort, M. Linscheid, M.A.M. Nawwar, Polyphenolic metabolites of Epilobium hirsutum, Phytochemistry, 46, 1997, 935-941.

[20] B.H. Tóth, B. Blazics, Á. Kéry, Polyphenol composition and antioxidant capacity of Epilobium species, J Pharmaceut Biomed, 49, 2009, 26-31.
[21] A. Vitalone, F. Bordi, C. Baldazzi, G. Mazzanti, L. Saso, B. Tita, Anti-proliferative effect on a prostatic epithelial cell line (PZHPV-7) by Epilobium angustifolium L., Farmaco, 56, 2001, 483-489.

[22] E. Ruszová, J. Cheel, S. Pávek, M. Moravcová, M. Hermannová, I. Matějková, J. Spilková, V. Velebný, L. Kubala, Epilobium angustifolium extract demonstrates multiple effects on dermal fibroblasts in vitro and skin photo-protection in vivo, Gen Physiol Biophys, 32, 2013, 347-359.

[23] V. Kaškonienė, M. Stankevičius, T. Drevinskas, I. Akuneca, P. Kaškonas, K.B. Survilienė , A.Maruška, O.Ragažinskienė, O. Kornyšova, V. Briedis, R. Ugenskienè, Evaluation of phytochemical composition of fresh and dried raw material of introduced Chamerion angustifolium L. using chromatographic, spectrophotometric and chemometric techniques, Phytochemistry, 115, 2015, 184-193.

[24] H.C. Onar, A. Yusufoglu, G. Turker, R. Yanardag, Elastase, tyrosinase and lipoxygenase inhibition and antioxidant activity of an aqueous extract from Epilobium angustifolium L. leave, J Med Plants Res, 6, 2012, 716-726.

[25] B.T. Hevesi, P.J. Houghton, S. Habtemariam, Á. Kéry, Antioxidant and anti-inflammatory effect of Epilobium parviflorum Schreb, Phytother Res, 23, 2009, 719-724.

[26] A.K. Kiss, A. Bazylko, A. Filipek, S. Granica, E. Jaszewska, U. Kiarszys, A. Kośmider, J. Piwowarski, Oenothein B's contribution to the anti-inflammatory and antioxidant activity of Epilobium sp., Phytomedicine, 18, 2011, 557-560.

[27] H. Juan, W. Sametz, A. Hiermann, Anti-inflammatory effects of a substance extracted from Epilobium angustifolium, Agents Actions, 23, 1988, 106-107.

[28] W.J. Bartfay, E. Bartfay, J.G. Johnson, Gram-negative and Grampositive antibacterial properties of the whole plant extract of Willowherb (Epilobium angustifolium), Biol Res Nurs, 14, 2012, 8589.

[29] L. Battinelli, B. Tita, M.G. Evandri, G. Mazzanti, Antimicrobial activity of Epilobium spp. Extracts, Farmaco, 56, 2001, 345-348.

[30] I. Kosalec, N. Kopjar, D. Kremer, Antimicrobial activity of Willowherb (Epilobium angustifolium L.) leaves and flowers, Curr Drug Targets, 14, 2013, 986-991.

[31] Q. Zeng, J. Wu, P. Lin, Chemical composition and antimicrobial activity of the essential oil from Epilobium angustifolium, Chem Nat Compd, 52, 2016, 1113-1115.

[32] S. Silló, E. Varga, Á. Belák, A. Maráz, Phytochemical and antimicrobial investigation of Epilobium angustifolium L., Acta Pharm Hung, 84, 2014, 105-110.

[33] B. Tita, H. Abdel-Haq, A. Vitalone, G. Mazzanti, L. Saso, Analgesic properties of Epilobium angustifolium, evaluated by the hot plate test and the writhing test, Farmaco 56, 2001, 341-343.

[34] M. Stolarczyk, M. Naruszewicz, A.K. Kiss, Extracts from Epilobium sp. herbs induce apoptosis in human hormonedependent prostate cancer cells by activating the mitochondrial pathway, J Pharm Pharmacol, 65, 2013, 1044-1054.

[35] F. Pourmorad, M.A. Ebrahimzadeh, M. Mahmoudi, S. Yasini, Antinociceptive activity of methanolic extract of Epilobium hirsutum, Pak J Biol Sci, 10, 2007, 2764-2767.

[36] F. Vitali, G. Fonte, A. Saija, B. Tita, Inhibition of intestinal motility and secretion by extracts of Epilobium spp. in mice, J Ethnopharmacol, 107, 2006, 342-348.

[37] E. Ehsan, M.R. Akhgar, A. Kariminik, Chemical constituents and antibacterial activity of the essential oil from Epilobium hirsutum, J Biodivers Environ Sci, 7, 2015, 338-344.

[38] I. Erik, G. Kiliç, E. Öztürk, Ş.A. Karaoğlu, N. Yaylı, Chemical composition, antimicrobial and lipase enzyme activity of essential oil and solvent extracts from Serapias orientalis subs. orientalis, Turk J Chem, in press, 2020.

[39] G. Tosun, N. Kahriman, C. Albay, Ş.A. Karaoğlu, N. Yaylı, Antimicrobial activity and volatile constituents of the flower, leaf, and stem of Paeonia daurica grown in Turkey, Turk J Chem, 35, 2011, 145-153. 
[40] G. Renda, A. Özel, B. Barut, B. Korkmaz, N. Yaylı, The Volatile chemical compositions of the essential oil/spme and enzyme inhibitory and radical scavenging activities of solvent extracts and the essential oils from Coronilla orientalis Miller and C. varia L. grows in Turkey, Iran J Pharm Res, 18, 2019, 1831-1842.

[41] B. Yaylı, G. Tosun, M. Karaköse, G. Renda, N. Yaylı, SPME/GCMS analysis of volatile organic compounds from three Lamiaceae species (Nepeta conferta Hedge \& Lamond, Origanum onites L. and Satureja cuneifolia Ten.) growing in Turkey, Asian J Chem, 26, 2014, 2541-2544.

[42] N. Yaylı, A. Yaşar, N. Yaylı, M. Albay, K. Coşkunçelebi, Essential oil analysis and antimicrobial activity of Paeonia mascula from Turkey, Nat Prod Commun, 3, 2008, 941-944.

[43] R.P. Adams, Identification of essential oil components by gas chromatography/mass spectrometry (4. edition), 2007, USA, Allured publishing Corporation.

[44] G.L. Woods, B.A. Brown-Elliott, P.S. Conville, E.P. Desmond, G.S. Hall, G. Lin, G.E. Pfyffer, J.C. Ridderhof, S.H. Siddiqi, R.J. Wallace Jr, N.G. Warren, F.G. Witebskyet, Susceptibility testing of mycobacteria, nocardiae, and other aerobic actinomycetes (2. Edition), 2011, USA, Clinical and Laboratory Standards Institute.

[45] A.L. Barry, W.A. Craig, H. Nadler, L. Barth Reller, C.C. Sanders, J.M. Swenson, Methods for determining bactericidal activity of antimicrobial agents; approved guideline (4. edition), 1999, USA, Clinical and Laboratory Standards Institute.

[46] R. Apak, K. Güçlü, B. Demirata, M. Özyürek, E.S. Çelik, B. Bektaşoğlu, I.K. Berker, D. Özyurt, Comparative evaluation of various total antioxidant capacity assays applied to phenolic compounds with the CUPRAC assay, Molecules, 12, 2007,14961547.

[47] M.S. Blois, Antioxidant determinations by the use of a stable free radical, Nature, 181, 1958, 1199-1200.

[48] R. Fu, Y. Zhang, Y. Guo, F. Chen, Antioxidant and tyrosinase inhibition activities of the ethanol-insoluble fraction of water extract of Sapium sebiferum (L.) Roxb. Leaves, S Afr J Bot, 93, 2014, 98-104.

[49] N.Y. Iskender, N. Yaylı, N. Yildrim, T.B. Cansu, S. Terzioglu, The volatile constituents of the flower, leaf, and stem of Verbascum wiedemannianum grown in Turkey, J Oleo Sci, 58, 2009, 117-121.

[50] O. Üçüncü, N. Yaylı, A. Yaşar, S. Terzioğlu, N. Yaylı, Chemical composition of the essential oils from flower, leaf, and stem of Senecio trapezuntinus Boiss. grown in Turkey, Nat Prod Commun, 3, 2008, 925-928.

[51] C.L. Cespedes, C. Balbontin, J. G. Avila, M. Dominguez, J. Alarcon, C. Paz, V. Burgos, L. Ortiz, I. Peñaloza-Castro, D.S. Seigler, I. Kubo, Inhibition on cholinesterase and tyrosinase by alkaloids and phenolics from Aristotelia chilensis leaves, Food Chem Toxicol, 109, 2017, 984-995.

[52] S. Momtaz, N.L. Basson, Inhibitory activities of mushroom tyrosine and DOPA oxidation by plant extracts, S Afr J Bot, 74, 2008, 577-582. 